\title{
Size distributions of elemental carbon in the atmosphere of a coastal urban area in South China: characteristics, evolution processes, and implications for the mixing state
}

\author{
X.-F. Huang ${ }^{1,2}$ and J. Z. Yu ${ }^{1,3}$ \\ ${ }^{1}$ Department of Chemistry, Hong Kong University of Science \& Technology, Clear Water Bay, Kowloon, Hong Kong, China \\ ${ }^{2}$ Shenzhen Graduate School, Peking University, Shenzhen, 518055, China \\ ${ }^{3}$ Atmospheric Research Center, HKUST Fok Ying Tung Graduate School, Nansha, Guangzhou 511458, China
}

Received: 30 May 2007 - Published in Atmos. Chem. Phys. Discuss.: 25 July 2007

Revised: 3 September 2008 - Accepted: 3 September 2008 - Published: 10 October 2008

\begin{abstract}
Elemental carbon (EC), as one of the primary light-absorbing components in the atmosphere, has a significant impact on both regional and global climate. The environmental impacts of EC are strongly dependent on its particle size. Little is known about the size distribution characteristics of EC particles in China's ambient environments. We report size distributions of EC particles in the urban area of Shenzhen in Southern China. In our samples, EC was consistently found in two modes, a fine mode and a coarse mode. The majority of EC mass ( $~ 80 \%)$ in this coastal metropolitan city resided in particles smaller than $3.2 \mu \mathrm{m}$ in diameter. The fine mode peaked at around either $0.42 \mu \mathrm{m}$ or $0.75 \mu \mathrm{m}$. While the mode at $0.42 \mu \mathrm{m}$ could be ascribed to fresh vehicular emissions in the region, the mode at $0.75 \mu \mathrm{m}$ was likely a result of particle growth from smaller EC particles. We theoretically investigated the particle growth processes that caused the EC particles to grow from $0.42 \mu \mathrm{m}$ to $0.75 \mu \mathrm{m}$ in the atmosphere. Our calculations indicate that the EC peak at $0.75 \mu \mathrm{m}$ was not produced through either coagulation or $\mathrm{H}_{2} \mathrm{SO}_{4}$ condensation; both processes are too slow to lead to significant EC growth. Hygroscopic growth was also determined to be insignificant. Instead, addition of sulfate through in-cloud processing was found to cause significant growth of the EC particles and to explain the EC peak at $0.75 \mu \mathrm{m}$. We also estimated the mixing state of EC from the EC size distributions. In the droplet size, at least $45-60 \%$ of the EC mass in the summer samples and $68 \%$ of the EC mass in the winter samples was internally mixed with sulfate as a result of in-cloud processing. This information on EC should be considered in models of the optical properties of aerosols in this
\end{abstract}

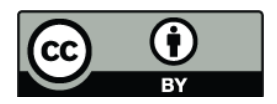

Correspondence to: J. Z. Yu (chjianyu@ust.hk) region. Our results also suggest that the in-cloud processing of primary EC particles could increase the light absorbing capacities through mixing EC with sulfate.

\section{Introduction}

Elemental carbon (EC) is an important component in atmospheric aerosols and is usually considered as the only particulate-phase light-absorbing species in the earth's radiation balance (Horvath, 1993; Jacobson, 2001). Current climatic models predict positive radiative forcing associated with EC (Hansen et al., 2000; Jacobson, 2001). Model simulations by Menon et al. (2002) indicate that EC emissions from China and India may be responsible for the increase in droughts in northeast China and flooding in southeast China during the summers that have been observed in the last 20 years. The highest EC concentrations are found in the atmosphere of urban areas due to widespread use of fossil fuels, such as in diesel- and gasoline-powered vehicles, while biomass burning acts as the largest source of $\mathrm{EC}$ on the global scale (Bond et al., 2004).

The light absorption efficiency of EC is a function of particle size, shape, composition, the mixing state with other aerosol species, as well as the wavelength of incident light (Fuller et al., 1999; Jacobson, 2001; Lesins et al., 2002; Chuang et al., 2003; Andreae and Gelencser, 2006). The absorbance coefficients of particles of internally mixed EC and sulfate ammonium are much higher than of particles of externally mixed EC and sulfate (Haywood and Shine, 1995; Seinfeld and Pandis, 1998). When EC-containing particles are freshly emitted, they are externally mixed with particles originally existing in the atmosphere. After emission,

Published by Copernicus Publications on behalf of the European Geosciences Union. 
various processes in the atmosphere, such as coagulation, vapor condensation, and in-cloud (or fog) processing, combine EC with other chemical species and consequently grow EC particles. By assuming different EC mixing states in a global climatic model, Jacobson (2000) showed that the positive radiative forcing of internally mixed EC was about three times higher than that from the externally mixed EC because of a larger absorption cross-section in the internal mixing case. It is clear that knowledge of EC size distributions is essential in accurately modeling the role of EC in modulating regional and global climate.

Atmospheric abundance of EC has been measured in bulk aerosols in numerous studies. The concentration of EC in bulk aerosols ranges from $0.2-2.0 \mu \mathrm{g} / \mathrm{m}^{3}$ in rural and remote areas to $1.5-20 \mu \mathrm{g} / \mathrm{m}^{3}$ in urban areas (Seinfeld and Pandis, 1998). In comparison, measurements of the size distributions of EC particles are considerably fewer, especially in the urban environments of China, including the Pearl River Delta (PRD) region, a fast-developing economic zone located on the southern coast of China. The ambient concentration levels of $\mathrm{EC}$ in $\mathrm{PM}_{2.5}$ or $\mathrm{PM}_{10}$ in the PRD region have been reported in a number of studies (e.g., Cao et al., 2004; Yu et al., 2004; Louie et al., 2005; Hagler et al., 2006). Hagler et al. (2006) measured EC in $\mathrm{PM}_{2.5}$ in the PRD region in different seasons during 2002-2003. They reported annual mean EC concentrations of $0.8-4.4 \mu \mathrm{g} / \mathrm{m}^{3}$ at seven different sites distributed across urban, regional, and rural surroundings. EC was found to be strongly influenced by local sources, with the highest levels in the urban areas.

Measurements in tunnel studies or dynamometer tests conducted in the US and Europe have mostly reported a unimodal distribution for EC with an mass medium aerodynamic diameter (MMAD) of $\sim 0.1 \mu \mathrm{m}$ (e.g., Venkataraman et al., 1994; Kerminen et al., 1997; Kleeman et al., 2000; Allen et al., 2001). The EC size distributions in urban areas were reported to be bimodal in the submicron size range in these developed countries with the peaks typically in the size range of $0.05-0.15 \mu \mathrm{m}$ (mode I) and $0.39-1.0 \mu \mathrm{m}$ (mode II) (e.g., Venkataraman and Friedlander, 1994; Berner et al., 1996; Hitzenberger and Tohno, 2001). The EC mode in the supermicron size range contained very little EC and was reported to peak at $4.65 \mu \mathrm{m}$ in one study (Hitzenberger and Tohno, 2001) and at 1.6-2.4 $\mu \mathrm{m}$ in another study (Berner et al., 1996). We report here measurements of EC size distributions in Shenzhen $\left(113.9^{\circ} \mathrm{E}, 22.6^{\circ} \mathrm{N}\right)$, a mega-city in the $\mathrm{PRD}$ region, and compare them with that of primary vehicular emissions recently measured in a roadway tunnel in this region by our group (Huang et al., 2006a). A second objective is to examine theoretically possible atmospheric processes that could lead to the EC size distributions observed in Shenzhen. A third objective is to estimate EC mixing states using the size distribution data and to discuss the implications. Such information is needed to model the radiative forcing of EC and hence to understand the role of EC as a modulator of regional and global climate.

\section{Aerosol sampling and chemical analysis}

The sample collection and chemical analysis details have been described in our previous paper (Huang et al., 2006b). A brief account is given here. The sampling site is on the rooftop of a 4-floor building ( $\sim 18 \mathrm{~m}$ above ground) on the campus of Shenzhen Graduate School, Peking University $\left(113.9^{\circ} \mathrm{E}, 22.6^{\circ} \mathrm{N}\right)$. The campus is located on the outskirts of the city, with no large roadways nearby. Size-segregated aerosol samples in the size range of $0.056-18 \mu \mathrm{m}$ were collected onto quartz fiber filter substrates using a ten-stage microorifice uniform deposit impactor (MOUDI) without rotation. MOUDI provides cut sizes of 18, 10, 5.6, 3.2, 1.8, 1.0, $0.56,0.32,0.18,0.10$, and $0.056 \mu \mathrm{m}$ in aerodynamic diameter when operating at a flow rate of $30 \mathrm{~L}, \mathrm{~min}^{-1}$. No after filter was used. Special spacers of 0.05 inch in thickness (MSP Corp.) were used to compensate for the reduced space between two adjacent impact plates due to the use of quartz fiber substrates. Nine sets of summer samples were collected during July-August 2004, and twelve sets of winter samples were collected from December 2004 to January 2005. Each sampling event lasted 48 or $72 \mathrm{~h}$.

Each filter substrate was analyzed for ionic species (i.e., $\mathrm{Cl}^{-}, \mathrm{NO}_{3}^{-}, \mathrm{SO}_{4}^{2-}$, oxalate, $\mathrm{Na}^{+}, \mathrm{NH}_{4}^{+}, \mathrm{K}^{+}, \mathrm{Mg}^{2+}$, and $\mathrm{Ca}^{2+}$ ), organic carbon (OC) and EC (Huang et al., 2006b). The OC/EC analysis was made on one quarter of each quartz filter using a thermal/optical transmittance aerosol carbon analyzer (Sunset Laboratory, OR, USA) (Birch and Cary, 1996). The temperature program for the thermal analysis was the same as that in the NIOSH method for diesel soot (NIOSH, 1999). Four temperature steps $(250,500,650$, and $850^{\circ} \mathrm{C}$ ) were used in the first stage analysis in helium, followed by another four temperature steps $(650,750,850$, and $940^{\circ} \mathrm{C}$ ) in the second stage analysis in $1 \% \mathrm{O}_{2} / 99 \% \mathrm{He}$. The entire analytical cycle was $580 \mathrm{~s}$ and $1 \% \mathrm{O}_{2}$ was introduced into the helium carrier gas at 360 s into the analysis. Due to the non-uniform deposition nature of the MOUDI samples, charring correction using optical transmittance is not appropriate for determining the $\mathrm{OC}$ and EC split point (Chow et al., 1993). For lack of a better alternative, the OC/EC split time was fixed at 360 s, i.e., with no charring correction. By our operational definition, $\mathrm{OC}$ is the fraction of carbon that evolved at or below $850^{\circ} \mathrm{C}$ in a helium atmosphere, and EC is the fraction of carbon that evolved after $1 \%$ oxygen was introduced to the carrier gas during an analytical cycle.

\section{Results and discussion}

\subsection{Determination of EC}

Non-uniform deposition in MOUDI impactor samples makes the optical charring correction scheme not operative as the sample collection is not uniform. Adopting an automatic split time provided by the thermal optical analyzer may bias 
Table 1. EC concentrations in fine and coarse particles in Shenzhen $\left(\mu \mathrm{g} / \mathrm{m}^{3}\right)^{a}$.

\begin{tabular}{|c|c|c|c|c|c|c|c|c|c|c|c|}
\hline Sample ID & $\begin{array}{c}\text { Sampling period } \\
\text { yy/mm/dd-dd }\end{array}$ & Temp Range $\left({ }^{\circ} \mathrm{C}\right)$ & $\mathrm{RH}$ range $(\%)$ & fine & coarse & Sample ID & $\begin{array}{l}\text { Sampling period } \\
\text { yy/mm/dd-dd }\end{array}$ & Temp Range $\left({ }^{\circ} \mathrm{C}\right)$ & $\mathrm{RH}$ range $(\%)$ & fine & coarse \\
\hline $\mathrm{S} 1$ & $04 / 07 / 21-22$ & $26-34$ & $46-92$ & 2.7 & 0.90 & $\mathrm{~W} 1$ & $04 / 12 / 14-15$ & $17-26$ & $35-80$ & 18.4 & 4.5 \\
\hline S2 & $04 / 07 / 23-24$ & $26-36$ & $39-82$ & 3.5 & 1.1 & W2 & $04 / 12 / 16-17$ & $16-27$ & $28-78$ & 13.1 & 2.8 \\
\hline S3 & $04 / 07 / 25-26$ & $27-35$ & $44-79$ & 2.3 & 0.72 & W3 & $04 / 12 / 18-19$ & $16-26$ & $44-80$ & 15.4 & 3.3 \\
\hline $\mathrm{S} 4$ & 04/08/12-13 & $27-35$ & $47-81$ & 7.2 & 1.4 & W4 & $04 / 12 / 20-21$ & $16-26$ & $45-83$ & 7.2 & 1.1 \\
\hline S5 & $04 / 08 / 14-16$ & $27-34$ & $48-91$ & 2.7 & 0.91 & W5 & $04 / 12 / 22-23$ & $18-28$ & $41-84$ & 6.8 & 1.8 \\
\hline S6 & $04 / 08 / 17-18$ & $28-37$ & $41-81$ & 11.4 & 2.5 & W6 & $04 / 12 / 24-25$ & $16-23$ & $53-70$ & 6.1 & 1.1 \\
\hline S7 & $04 / 08 / 21-23$ & $25-35$ & $52-89$ & 4.2 & 1.0 & W7 & $04 / 12 / 26-27$ & $16-25$ & $47-79$ & 4.1 & 0.93 \\
\hline S8 & $04 / 08 / 24-26$ & $26-36$ & $48-89$ & 4.7 & 1.1 & W8 & $04 / 12 / 28-29$ & $7-16$ & $47-79$ & 3.8 & 0.53 \\
\hline \multirow[t]{4}{*}{ S9 } & 04/09/01-03 & $27-35$ & $45-88$ & 2.2 & 0.61 & W9 & $04 / 12 / 30-31$ & $7-15$ & $25-68$ & 3.3 & 0.67 \\
\hline & & & & & & W10 & 05/01/01-02 & $5-15$ & $14-55$ & 3.9 & 0.81 \\
\hline & & & & & & W11 & 05/01/03-04 & $8-19$ & $39-70$ & 7.7 & 1.5 \\
\hline & & & & & & W12 & 05/01/05-06 & $13-23$ & $38-70$ & 7.3 & 0.80 \\
\hline AVE & & & & 4.5 & 1.1 & & & & & 8.1 & 1.6 \\
\hline SD & & & & 3.0 & 0.58 & & & & & 4.9 & 1.2 \\
\hline
\end{tabular}

$a$ The EC concentrations might be overestimated because no charring correction was considered in the thermal analysis.

the EC values low because of an erroneously high initial filter transmittance. The erroneous high initial transmittance happens when the laser beam for filter transmittance monitoring passes through blank filter space in between aerosol deposits. Jaffrezo et al. (2005) found that EC in impactor samples determined by using the automatic split times was only $76 \%$ of the EC in collocated filter-based samples, in which the aerosol deposition was uniform. Similar results (71\%) were obtained by ten Brink et al (2004). A much lower value $(25 \%)$ was reported in the work by Viidanoja et al (2002). It is clear from these studies that the conventional optical charring correction scheme is not applicable to the non-uniform aerosol deposit samples such as impactor samples.

EC determined without charring correction leads to an upper limit in the estimation of the real EC. This overestimation error was shown in the study by Viidanoja et al. (2002) to be within $30 \%$ of the EC determined for the collocated filter-based samples with proper optical charring correction. They also showed that EC in impactor samples determined with no charring correction agreed within $30 \%$ error with BC measured by an aethalometer. With their data, Viidanoja et al. concluded that the lack of charring correction for their impactor samplers did not cause significant errors in the OC/EC split. Thus, we conclude that the choice of applying no charring correction is better than using the automatic split time for the determination of $\mathrm{EC}$ in the non-uniform impactor samples.

While we acknowledge the uncertainty in EC concentration measurements with the no charring correction approach, our analysis described below indicates that the size bin of the EC modal peak, which is the focus of this work, is insensitive to whether charring correction is applied or not. We first varied the OC/EC spit time from 360s (i.e., with no charring correction) to $420 \mathrm{~s}$, the typical split time range found for bulk aerosol samples in this region. Figure 1 shows an example of size distribution of EC obtained using three different fixed split time positions (360, 400, and 420s). As expected, the EC concentrations depend strongly on where the split point is set. The EC concentrations obtained without charring correction could be up to double those obtained with the split time set at $420 \mathrm{~s}$. However, the different split times had little impact on the size distribution pattern. That is, regardless of the OC/EC split position, EC always had a dominant fine mode in the same size bin $(0.56-1.0 \mu \mathrm{m}$ in this example). In the above analysis, charring correction was made at an EC/OC split time fixed for samples of all size bins. One may argue that the fraction of charred OC may vary with the stages; however, this variation is small between samples of adjacent stages due to similar chemical compositions. The three stages that define the EC modal peak in the accumulation size range are $0.32-0.56 \mu \mathrm{m}, 0.56-1.0 \mu \mathrm{m}$, and 1.0 $1.8 \mu \mathrm{m}$. We found that water-soluble organic carbon, which is the portion of OC more prone to charring (Yu et al., 2002), had similar mass percentage contributions $(0.15,0.14$, and 0.12 in the size bins of $0.32-0.56 \mu \mathrm{m}, 0.56-1.0 \mu \mathrm{m}$, and 1.0 $1.8 \mu \mathrm{m}$, respectively) (Huang et al., 2006b). In summary, we conclude that the uncertainty about the EC/OC split point does not affect the discussion below on the evolution of EC size distributions.

\subsection{EC size distributions}

Table 1 lists the EC concentrations in the fine $(<3.2 \mu \mathrm{m}$ in diameter) and coarse particles ( $>3.2 \mu \mathrm{m}$ in diameter) in the individual samples. The fine mode EC had an average concentration of $4.5 \mu \mathrm{g} / \mathrm{m}^{3}$ in the summer samples and $8.1 \mu \mathrm{g} / \mathrm{m}^{3}$ in the winter samples. The fine mode EC accounted for approximately $80 \%$ of the total EC in both the summer and the winter samples. The higher concentrations of EC in the winter were a combined result of the unfavorable atmospheric dispersion conditions and the infrequent wet removal in the winter in the PRD region (Yuan et al., 2006a). 


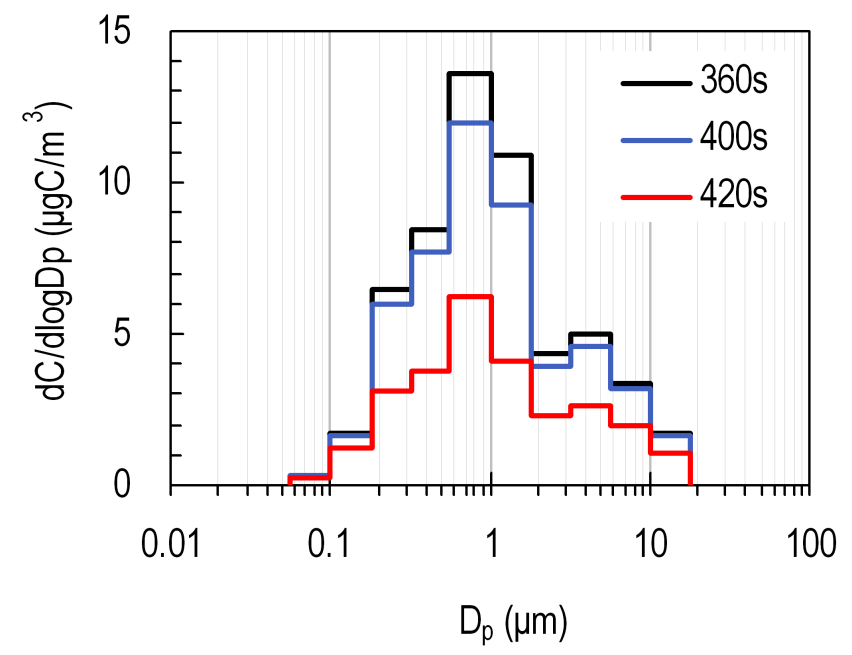

Fig. 1. Comparison of EC size distributions using different OC/EC split times.

The average EC size distributions in the summer and the winter samples are shown and compared with the EC size distribution obtained in a roadway tunnel in this region in Fig. 2. The ambient EC showed a common bimodal pattern, with a major fine mode and a minor coarse mode. While the coarse mode always peaked in the size bin of $3.2-5.6 \mu \mathrm{m}$, the fine mode peaked in one of the two size bins of 0.32 $0.56 \mu \mathrm{m}$ and $0.56-1.0 \mu \mathrm{m}$. Among the nine sets of the summer samples, six sets with lower EC concentrations (Group L) peaked in the $0.32-0.56 \mu \mathrm{m}$ size bin while the other three sets with higher EC concentrations (Group H) peaked in the $0.56-1.0 \mu \mathrm{m}$ size bin. The average EC size distributions of Groups $\mathrm{L}$ and $\mathrm{H}$ were also shown in Figure 2a. In comparison, all twelve sets of the winter samples consistently showed a fine mode EC peak in the $0.56-1.0 \mu \mathrm{m}$ size bin. This is a logical result of frequent wet removal of aged aerosols $(0.56-1.0 \mu \mathrm{m})$ in the summer, leading to a more prominent presence of freshly emitted EC $(0.32-0.56 \mu \mathrm{m})$. The rainfall amount in the summer sampling periods was recorded to be $495 \mathrm{~mm}$ while there was only $6 \mathrm{~mm}$ rainfall in the winter sampling periods.

The fine mode EC peaking in the $0.32-0.56 \mu \mathrm{m}$ size bin was consistent with a situation in which the ambient EC particles were dominated by freshly emitted EC particles from vehicular emissions. The study by Hagler et al. (2006) on the temporal and spatial distribution of major aerosol constituents in $\mathrm{PM}_{2.5}$ indicated that local vehicular exhaust was the dominant source of EC in the urban atmosphere in the PRD region. The size distribution characteristics of EC particles from vehicular emissions in this region were previously measured in a roadway tunnel by our group and were found to exhibit a dominant fine mode peaking in the $0.32-0.56 \mu \mathrm{m}$ size bin (Fig. 2c) (Huang et al., 2006a). The dominance of freshly emitted EC particles from vehicles is possible after
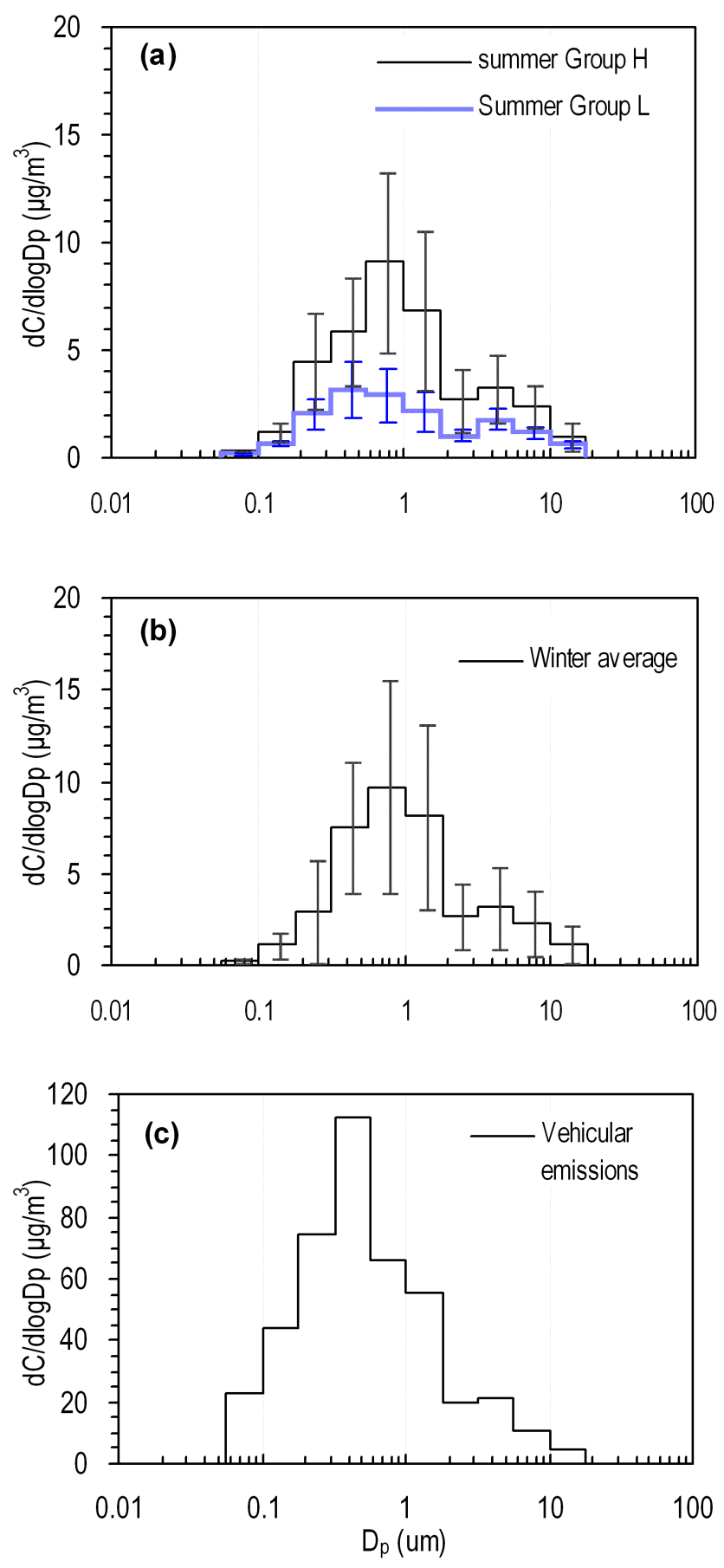

Fig. 2. Average EC size distributions in ambient samples and in vehicular emissions. The error bars represent one standard variations among different samples in the same sample group.

a heavy rain event removes most of the aged EC particles. For example, the monitoring data by the Hong Kong Environment Protection Department show that the OC/EC ratios in $\mathrm{PM}_{10}$ samples collected after more than $15 \mathrm{~mm}$ rainfall on the previous day were typically found to be less than 1 (Yuan 
et al., 2006a), closer to the low end of the range of 0.74-2.4 for the OC/EC ratios for primary carbonaceous aerosols in various urban areas reported in the literature (e.g., Kadowaki, 1990; Cabada et al., 2002).

In comparison with freshly emitted EC from vehicles, in all the winter samples and in three of the summer samples collected in this study, the ambient EC modal peak shifted to the $0.56-1.0 \mu \mathrm{m}$ size bin. It is unlikely that such a shift in size could be caused by particle bounce from the coarse mode impactor stages to the smaller ones, since the collection substrate was quartz fiber filters. Glass fiber filters, with which quartz fiber filters share the common fibrous mat structure, have been demonstrated to cause little particle bounce as a result of partial entrainment of collected particles into the fibrous mat (Chang et al., 1999).

The possibility of EC emissions from biomass burning to account for the larger EC mode can also be excluded for the following reasons. First, fresh EC emissions from biomass burning have been shown in a number of studies to have a modal peak at a size less than $0.3 \mu \mathrm{m}$ in diameter (e.g., Remer et al., 1998; Kleeman et al., 1999). Second, available data on ambient aerosols in this region indicated that biomass burning was a minor source of EC particles. Yuan et al (2006b) reported source profiles and contributions of major $\mathrm{PM}_{10}$ sources in Hong Kong (a neighboring city to Shenzhen) derived using positive matrix factorization (PMF) analysis of more than $2000 \mathrm{PM}_{10}$ measurements. Estimation based on the PMF-derived source profiles and contributions indicated that vehicular exhaust was the dominant primary EC source $(\sim 80 \%)$ and biomass burning accounted for less than $1 \%$ of EC in ambient $\mathrm{PM}_{10}$ in Hong Kong during summertime (Yuan et al., 2006b).

In summary, the shift of the EC modal peak to the 0.56$1.0 \mu \mathrm{m}$ size bin is mostly a result of atmospheric aging of fresh EC after emissions. What is the mechanism responsible for the growth of fresh EC particles to the 0.56-1.0 $\mu \mathrm{m}$ mode in this region? This is an important question because the particle size of EC strongly influences its lifetime and optical properties in the atmosphere. We present below a theoretical investigation aiming to identify the mechanism responsible for this growth process.

\subsection{Theoretical analysis of EC growth mechanisms}

To explain the presence of the $0.56-1.0 \mu \mathrm{m}$ mode is in essence to identify a mechanism by which EC particles in the $0.32-0.56 \mu \mathrm{m}$ size bin grow to $0.56-1.0 \mu \mathrm{m}$. In the atmosphere, aerosol particles can grow in size through several mechanisms, including water accretion, coagulation, vapor condensation, and addition of materials formed through heterogeneous or in-cloud (or fog) aqueous reactions. To quantify the extent of growth by the various processes, we consider the number size distributions and the thermodynamic properties of the aerosol particles. The number size distributions were estimated from the measured mass size distri-

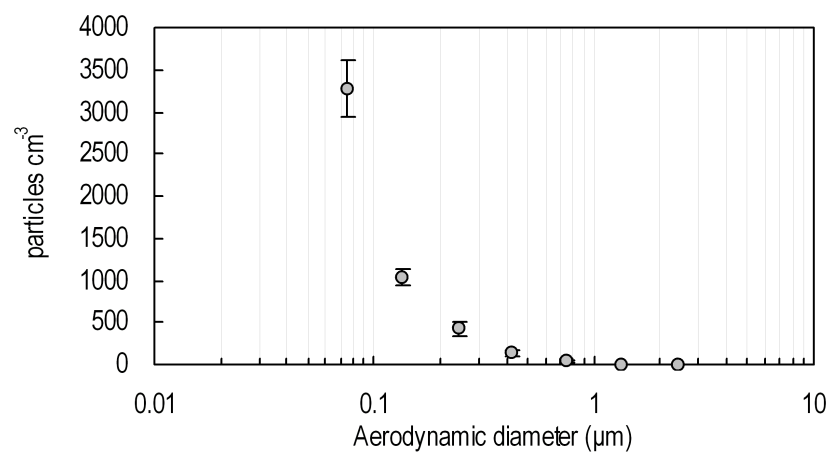

Fig. 3. Number size distribution derived from the average mass size distribution of summer Group L samples. The error bars represent one standard variation among the six sets of summer Group L samples.

butions with the following consideration: (1) all particles in each size bin were assumed to have the mean diameter and the same chemical composition; (2) the particle density in each size bin was the mass-weighted average density of the measured major constituents, including $\mathrm{EC}, \mathrm{OC}, \mathrm{NO}_{3}^{-}$, $\mathrm{SO}_{4}^{2-}, \mathrm{NH}_{4}^{+}$, and $\mathrm{H}_{2} \mathrm{O}$; (3) contributions of the aerosol water content were calculated using an aerosol thermodynamic model, ISORROPIA (Nenes et al., 1998) and assuming a relative humidity $(\mathrm{RH})$ of $78 \%$, the mean value during the summer sampling periods; and (4) crustal materials were not included in the chemical composition on the basis that they usually contributed little to the total mass in fine aerosol particles. Considering that Group L aerosols represented relatively freshly emitted particles, we used the average aerosol size distributions of the Group L aerosols to approximate the initial particle population for growth estimation. The derived number size distribution is shown in Fig. 3. The variations in particle number concentrations among different Group L samples ranged from $10 \%$ to $33 \%$ for the seven size bins in the size range of $0.056-3.2 \mu \mathrm{m}$ (Fig. 3). The variations were $22 \%$ and $24 \%$ for the two size bins under consideration, i.e., $0.32-0.56 \mu \mathrm{m}$ and $0.56-1.0 \mu \mathrm{m}$, respectively.

The particle density value needed for the calculation of the number distribution is also an important source contributing to the uncertainty of the derived number size distribution. The particle density was estimated to range from 1.08$1.19 \mathrm{~g} \mathrm{~cm}^{-3}$. The density values used for the major constituents were $1 \mathrm{~g} \mathrm{~cm}^{-3}$ for water, $1.78 \mathrm{~g} \mathrm{~cm}^{-3}$ for ammonium sulfate and nitrate, $1.0 \mathrm{~g} \mathrm{~cm}^{-3}$ for organic matter, and $1.0 \mathrm{~g} \mathrm{~cm}^{-3}$ for EC. Among them, the density of EC is most uncertain and the values in the literature range from 0.625 to $2.25 \mathrm{~g} \mathrm{~cm}^{-3}$ (Fuller et al., 1999). The particle number concentrations estimated using the two extreme EC density values do not deviate more than $10 \%$ from the particle number concentration obtained with an assumed EC density of $1 \mathrm{~g} \mathrm{~cm}^{-3}$. 


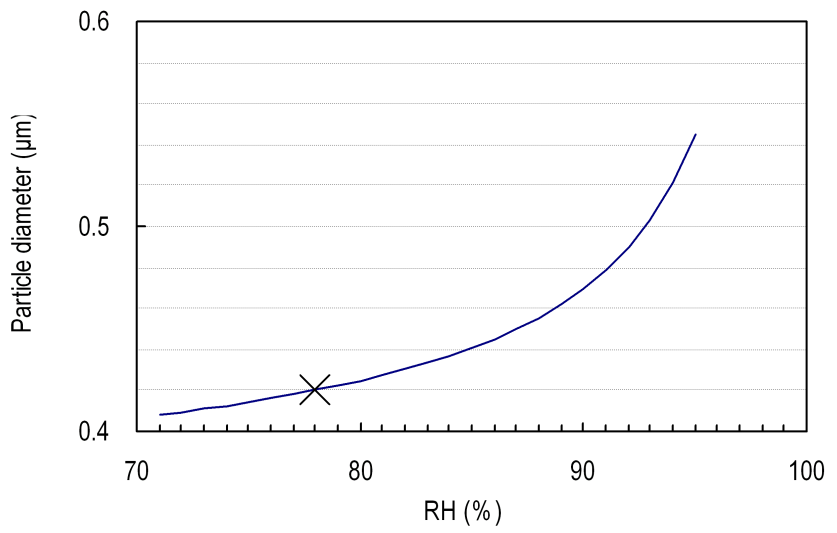

Fig. 4. Hygroscopic growth of particles at $0.42 \mu \mathrm{m}$ in the summer (the cross corresponding to $0.42 \mu \mathrm{m}$ at $\mathrm{RH} 78 \%$, the mean $\mathrm{RH}$ value during the summer sampling periods).

The magnitude of uncertainty associated with either sample-to sample variation or with the assumed particle density was found not to qualitatively alter conclusions drawn from various calculations for the growth mechanisms, which are described later in details in this section.

The temporal and spatial scales relevant to our discussion are described below. We define the so-called "local" region to be the entire highly urbanized PRD region of about $2^{\circ} \times 2^{\circ}(200 \mathrm{~km} \times 200 \mathrm{~km})$. Backward trajectories of $100,500,1000$, and $1500 \mathrm{~m}$ above ground were calculated for all the summer sampling days using the hybrid single-particle Lagrangian integrated trajectories (HYSPLIT) model (Draxler and Rolph, 2003; Rolph, 2003). The back trajectory calculations indicated that air masses resided in the PRD region for about $12-24 \mathrm{~h}$ before they were transported outside. We adopted one day as the upper limit for the residence time of locally emitted EC in the PRD region.

\subsubsection{Hygroscopic growth}

When RH increases, hygroscopic components in particles absorb water. The amount of water accretion can be calculated using the thermodynamic model ISORRPIA. Figure 4 shows the calculated particle growth as a function of ambient RH from 70 to $95 \%$ when a particle of $0.42 \mu \mathrm{m}$ (the mean diameter of the $0.32-0.56 \mu \mathrm{m}$ size bin) absorbs water. The particle at most grows to $0.54 \mu \mathrm{m}$ by water accretion when RH increases to $95 \%$. Such a high RH rarely occurs on nonprecipitation days. During the sampling periods, RH ranged from $14 \%$ to $92 \%$ (Table 1). This means that water accretion is not a viable mechanism for the EC particles in the 0.32 $0.56 \mu \mathrm{m}$ range to grow to the next size bin of $0.56-1.0 \mu \mathrm{m}$.

\subsubsection{Coagulation}

Collision of particles can result in the coagulation of particles and hence particle growth in size. Coagulation of particles in

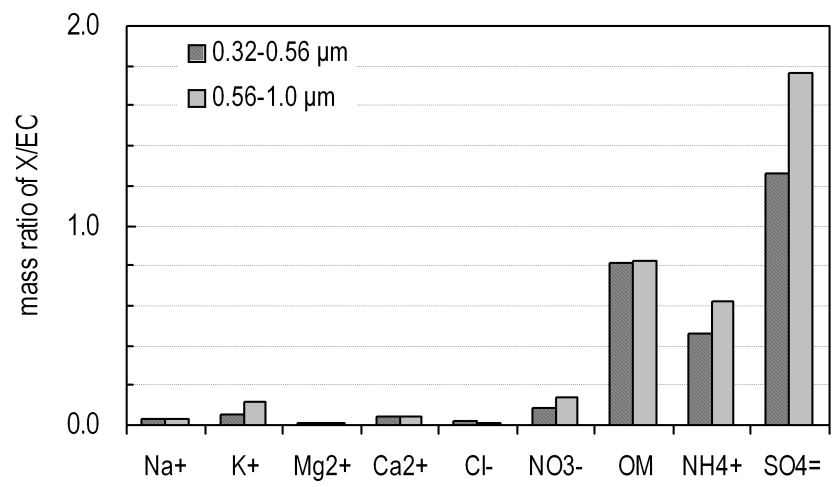

Fig. 5. Comparison of the abundances of major constituents relative to EC in the $0.32-0.56 \mu \mathrm{m}$ and $0.56-1.0 \mu \mathrm{m}$ size bins of Group $\mathrm{H}$ samples.

the atmosphere is dominated by Brownian motion (Wexler et al., 1994). Diffusion coagulation between a smaller particle and a larger particle depletes the smaller particle but does not cause significant particle growth while coagulation between particles of similar sizes is effective for particle growth. When two particles of the same size collide, the resulting particle has a mass equivalent diameter up to 1.3 times that of the original one (Kerminen and Wexler, 1995). The nature of coagulation dictates that while coagulation is an effective mechanism for transfer of particles from the nuclei mode $(<0.1 \mu \mathrm{m})$ to the accumulation mode, it is a slow process for growth of particles in the accumulation mode size range (Seinfeld and Pandis, 1998).

We estimated the time needed for the $0.32-0.56 \mu \mathrm{m}$ size bin to grow into the next size bin of $0.56-1.0 \mu \mathrm{m}$ by coagulation. The number concentration of particles in the 0.32 $0.56 \mu \mathrm{m}$ size bin was $\sim 200 \mathrm{~cm}^{-3}$ during our summer sampling period. Assuming an upper value of the coagulation coefficient, $\mathrm{K}$, of $10^{-9} \mathrm{~cm}^{-3} \mathrm{~s}^{-1}$ (Kerminen and Wexler, 1995), we calculated that the time required was at least eight days to grow particles to the $0.56-1.0 \mu \mathrm{m}$ size bin. This time scale was too slow to account for the observed EC mode shift.

\subsubsection{Vapor condensation}

Particle growth by condensation of gaseous species, heterogeneous reactions, and in-cloud processing is all related to the addition of new aerosol materials. We first identify the new aerosol materials that are primarily responsible for the EC particle growth in our ambient environment. This was achieved by comparing the relative abundance of the major aerosol components to EC in the two size bins $(0.32-0.56 \mu \mathrm{m}$ and $0.56-1.0 \mu \mathrm{m}$ ) in the Group H samples (Fig. 5). Only sulfate and ammonium were significantly more abundant in the $0.56-1.0 \mu \mathrm{m}$ size bin than in the $0.32-0.56 \mu \mathrm{m}$ size bin. This comparison identified sulfate and ammonium to be the aerosol materials responsible for EC particle growth. Ammonium and sulfate in the two size bins had a molar ratio 


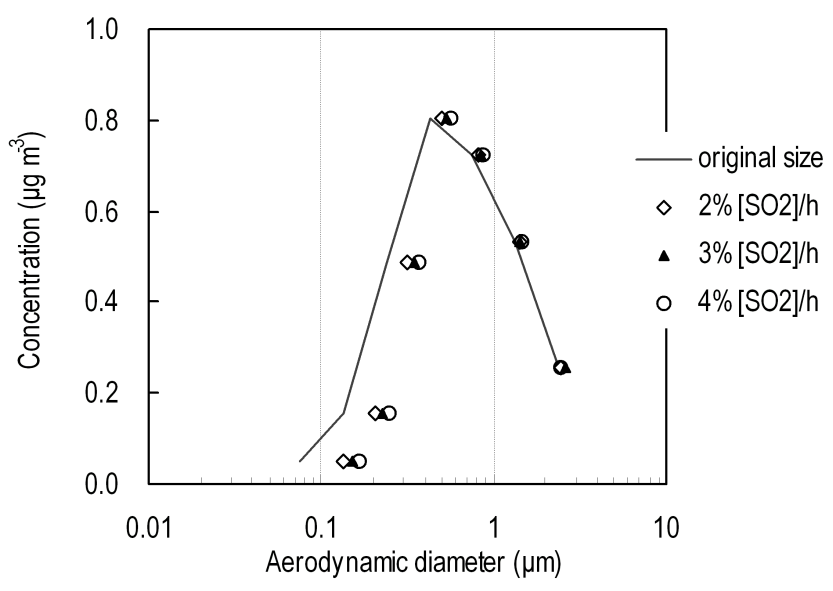

Fig. 6. Particle growth through $\mathrm{H}_{2} \mathrm{SO}_{4}$ vapor condensation. Three $\mathrm{H}_{2} \mathrm{SO}_{4}$ formation rates, $2 \%, 3 \%$, and $4 \%\left[\mathrm{SO}_{2}\right] / \mathrm{h}$, were assumed corresponding to $[\mathrm{OH}]$ concentrations of $0.5,0.75$, and $1.0 \times 10^{7}$ molecules $\mathrm{cm}^{-3}$, respectively.

of 1.9 and 2.0, respectively, indicating that ammonium sulfate was their main aerosol phase form. We next considered secondary formation of ammonium sulfate and subsequent addition to the existing EC particles in the size bin of 0.32$0.56 \mu \mathrm{m}$.

Among the secondary formation pathways of sulfate aerosol, in-cloud aqueous oxidation of $\mathrm{SO}_{2}$ has been established to be the dominant mechanism, contributing 50$80 \%$ of the conversion from $\mathrm{SO}_{2}$ to sulfate in the troposphere, followed by gas-phase photochemical oxidation of $\mathrm{SO}_{2}$ (Langner and Rodhe, 1991; McHenry and Dennis, 1994; Seinfeld and Pandis, 1998; Warneck, 1999). Heterogeneous oxidation of $\mathrm{SO}_{2}$ on the solid particle surface or in the liquid surface layer of particles is insignificant in submicron particles (Saxena and Seigneur, 1987; Meng and Seinfeld, 1994; Liang and Jacobson, 1999; Kerminen et al., 2000). Therefore, heterogeneous reactions are excluded as a viable mechanism leading to the significant growth of EC particles in Shenzhen.

Of the gas-phase oxidation reactions of $\mathrm{SO}_{2}$, the reaction with $\mathrm{OH}$ radicals is the dominant pathway, especially in urban environments. The rate constant for this reaction at $298 \mathrm{~K}$ is $1.2 \times 10^{-12}$ molecule ${ }^{-1} \mathrm{~cm}^{3} \mathrm{~s}^{-1}$. In our calculations, we assume an $\mathrm{SO}_{2}$ concentration of $10 \mathrm{ppb}$, the mean concentration level in the summer in Shenzhen (SZEPB, 2006). As there is no available measurement of the $\mathrm{OH}$ radical concentration in this region, we adopted three $[\mathrm{OH}]$ values, $0.5,0.75$, and $1 \times 10^{7}$ molecules $\mathrm{cm}^{-3}$, in the typical range of summer time [OH] (i.e., $0.5 \sim 1 \times 10^{7}$ molecules $\mathrm{cm}^{-3}$ ) (Seinfeld and Pandis, 1998). The gas-phase $\mathrm{H}_{2} \mathrm{SO}_{4}$ production rate was calculated to be $2 \%, 3 \%$, and $4 \%\left[\mathrm{SO}_{2}\right] \mathrm{h}^{-1}$ at the three $\mathrm{OH}$ concentrations, respectively. The time for active photochemical reactions was set to be $8 \mathrm{~h}$ per summer day, resulting in a

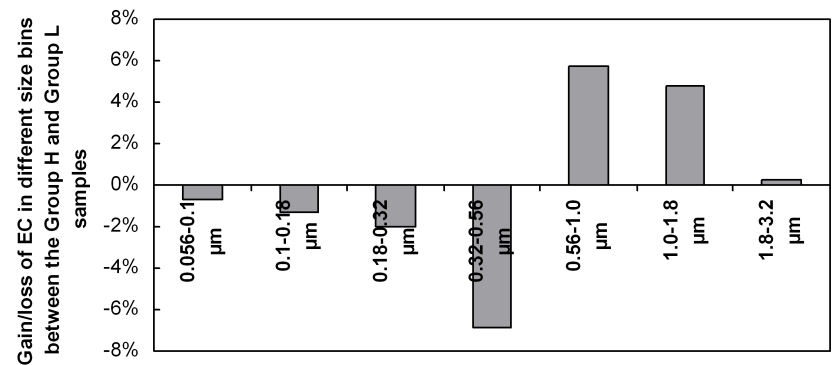

Fig. 7. Gain or loss of EC in different size bins when Group L aerosol population evolves to Group $\mathrm{H}$ aerosol population.

total $\mathrm{SO}_{4}^{2-}$ production of $6.3,9.5$, and $13 \mu \mathrm{g} \mathrm{m}^{-3}$ at the three production rates, respectively.

The newly formed gas-phase $\mathrm{H}_{2} \mathrm{SO}_{4}$ subsequently condenses on available particle surfaces. The particle-sizedependent condensation flux can be expressed as (Pandis et al., 1993):

$J_{i}=2 \pi D_{p} D_{i}\left(C_{a, i}-C_{e, i}\right) /(\beta+1)$,

where $D_{p}$ is the particle diameter, $D_{i}$ is the molecular diffusivity of the condensate, $i$, and $C_{a, i}$ and $C_{e, i}$ are the ambient concentration and the equilibrium particle surface concentration, respectively. The $\beta$ value is equal to $2 \lambda / \alpha D_{p}$, where $\alpha$ is the accommodation coefficient and $\lambda$ is the mean free path of air. The $\alpha$ value of $\mathrm{H}_{2} \mathrm{SO}_{4}$ was assumed to be sizeindependent and set at 0.12 (Ervens et al., 2003). Eq. (1) indicates that the overall transfer rate to particles in a size bin depends on $n\left(D_{p}\right) J_{i}$, where $n\left(D_{p}\right)$ is the number of particles of diameter $D_{p}$. A constant $C_{e, i}$ of $\mathrm{H}_{2} \mathrm{SO}_{4}$ was also assumed for all particles. The fraction of the condensed $\mathrm{H}_{2} \mathrm{SO}_{4}$ in each size bin can be calculated from Eq. (1). About $17 \%$ of $\mathrm{H}_{2} \mathrm{SO}_{4}$ was estimated to condense on particles in the $0.32-0.56 \mu \mathrm{m}$ size bin. We next assumed that the condensed $\mathrm{H}_{2} \mathrm{SO}_{4}$ were neutralized by sufficient $\mathrm{NH}_{3}$ to form $\left(\mathrm{NH}_{4}\right)_{2} \mathrm{SO}_{4}$, which caused corresponding increase of aerosol water content. The new particle size after addition of $\left(\mathrm{NH}_{4}\right)_{2} \mathrm{SO}_{4}$ and water can thus be obtained. Figure 6 shows the new size distribution of EC after sulfate condensation growth. It can be seen that the EC particles originally with a $0.42 \mu \mathrm{m}$ diameter grow to $0.50,0.53$ and $0.56 \mu \mathrm{m}$ in the three scenarios, respectively.

It may be argued that approximately half of the $0.56 \mu \mathrm{m}$ particles would be collected into the $0.56-1.0 \mu \mathrm{m}$ size bin and counted as particles in the $0.56-1.0 \mu \mathrm{m}$ size bin since the collection efficiency of MOUDI impactors is not a step function. Further analysis described below negated such a possibility. If we compare the relative EC distributions in different size bins in the size range of $0.056-3.2 \mu \mathrm{m}$ between the average Group $\mathrm{H}$ and Group L samples, we find 5-6\% gain of EC in the $0.56-1.0$ and $1.0-1.8 \mu \mathrm{m}$ size bins in the average Group $\mathrm{H}$ sample and 1-7\% loss of EC in the four size bins in the $0.056-0.56 \mu \mathrm{m}$ size range (Fig. 7). Of the $7 \%$ loss 
from the $0.32-0.56 \mu \mathrm{m}$ size bin, about half of the mass is above $0.42 \mu \mathrm{m}$, implying that up to half can be incorporated into the next size bin $(0.56-1.0 \mu \mathrm{m})$. This translates to that no more than ca. $2 \%(7 \% \times 0.5 \times 0.5)$ of the mass from the $0.32-56 \mu \mathrm{m}$ size bin can be transferred to $0.56-1.0 \mu \mathrm{m}$ size bin via condensation growth. This $2 \%$ change from condensational growth can not be accounted for the $6 \%$ gain in the $0.56-1.0 \mu \mathrm{m}$ size bin that has been observed. Similar arguments can be made that the EC gain in the next larger size bin $(1.0-1.8 \mu \mathrm{m})$ can not be accounted for by growth of particles by condensation from the $0.56-1.0 \mu \mathrm{m}$ size bin. EC particles having the mean diameter $(0.78 \mu \mathrm{m})$ of particles in the $0.56-$ $1.0 \mu \mathrm{m}$ size bin could only grow to $0.81,0.84$, and $0.88 \mu \mathrm{m}$ in the three scenarios of vapor condensation described in Figure 6 , much smaller than the cut off size of $1.0 \mu \mathrm{m}$ in the 1.0 $1.8 \mu \mathrm{m}$ size bin. We therefore conclude that condensation of $\mathrm{H}_{2} \mathrm{SO}_{4}$ produced in the gas-phase alone could not explain the observed particle growth to the $0.56-1.0 \mu \mathrm{m}$ and $1.0-1.8 \mu \mathrm{m}$ size bins from their respective next smaller size bins.

\subsubsection{In-cloud processing}

Stratus and stratocumulus are the two most common lowlevel clouds the are found at about $0-2 \mathrm{~km}$ from the ground and thus can significantly promote atmospheric aqueous chemical reactions in the mixing layer (Meng and Seinfeld, 1994; Seinfeld and Pandis, 1998). The average cloud cover in this coastal region in summer is about $70 \%$ (www.hko.gov.hk). Assuming a typical updraft velocity of $0.05 \mathrm{~m} / \mathrm{s}$ for stratus and stratocumulus clouds (Venkataraman et al., 2001), we calculated that all air mass in the mixing layer ( $\sim 1.2 \mathrm{~km}$ in summer, Yuan et al., 2006a) could experience in-cloud processing within a day.

Aqueous-phase $\mathrm{SO}_{2}$ oxidation in clouds is dominated by $\mathrm{H}_{2} \mathrm{O}_{2}$ oxidation (Seinfeld and Pandis, 1998; Liang and Jacobson, 1999; Warneck et al., 1999). The $\mathrm{H}_{2} \mathrm{O}_{2}$ oxidation reaction proceeds very quickly and is independent of $\mathrm{pH}$. The aqueous oxidation rate of $\mathrm{SO}_{2}$ by $\mathrm{H}_{2} \mathrm{O}_{2}$ is $700 \% \mathrm{SO}_{2}$ $\mathrm{h}^{-1}\left(\mathrm{~g} \text { water } / \mathrm{m}^{3}\right)^{-1}$ at an $\mathrm{H}_{2} \mathrm{O}_{2}$ concentration of $1 \mathrm{ppb}(\mathrm{Se}-$ infeld and Pandis, 1998). Considering the fast reaction kinetics of $\mathrm{SO}_{2}$ oxidation by $\mathrm{H}_{2} \mathrm{O}_{2}$, we estimate the newly formed sulfate mass by multiplying this reaction rate with a singlevalued cloud water content and an assumed typical cloud cycle duration. In stratus and stratocumulus clouds, the typical water content is $\sim 0.3 \mathrm{~g} \mathrm{~m}^{-3}$ and a typical cloud cycle is $\sim 40$ min (Seinfeld and Pandis, 1998; Feingold et al., 1998; Venkataraman et al., 2001). Such a cloud cycle is estimated to convert $140 \%$ of the gaseous $\mathrm{SO}_{2}$ to sulfate (i.e., $42 \mu \mathrm{g}$ $\mathrm{m}^{-3}$ sulfate corresponding to $10 \mathrm{ppb}$ gaseous $\mathrm{SO}_{2}$ ) at the assumed $\mathrm{H}_{2} \mathrm{O}_{2}$ and $\mathrm{SO}_{2}$ concentrations in an open system scenario. The newly formed $\mathrm{SO}_{4}^{2-}$ adds onto the particles that have been activated to form liquid droplets. It is assumed that the new sulfate mass was equally distributed among individual CCN particles. Upon cloud evaporation, residue particles of larger diameters are formed and the new particle diame- ters can be calculated from the sum of the original particle mass and the mass of the sulfate ammonium newly acquired from the in-cloud processing and the additional absorbed water due to increased solute concentration in the residual particles.

To estimate the particle growth, we first need to calculate the number of particles that are activated to form droplets prior to experiencing in-cloud processing. The saturation ratio $(S)$ necessary for cloud activation of a particle of $D_{p}$ in diameter containing insoluble substance (e.g., EC) is given by:

$$
\ln S=\frac{A}{D_{p}}-\frac{B}{D_{p}^{3}-d_{u}^{3}},
$$

where $A=4 \sigma V_{w} / \mathrm{RT}, \mathrm{B}=6 n_{s} V_{w} / \pi, d_{u}$ is the equivalent diameter of the insoluble material and can be obtained by removing contribution of water and soluble mass from a particle of $D_{p}, \sigma$ is the surface tension and approximated to be that for pure water $\left(0.0761 \mathrm{~J} \mathrm{~m}^{-2}\right), V_{w}$ is the molar volume of water $\left(1.8 \times 10^{-5} \mathrm{~m}^{3} \mathrm{~mol}^{-1}\right)$, and $n_{s}$ is the number of moles of solute in the particle, which can be calculated from the observed particle composition. The maximum point of the Köhler curve resulting from Eq. (2) indicates the supersaturation necessary for activating particles of a certain size. Our calculation predicts that the critical supersaturation values $\left(S_{c}\right)$ required to activate particles of $0.056,0.1,0.18$, and $0.32 \mu \mathrm{m}$ are $0.8 \%, 0.3 \%, 0.1 \%$, and $0.04 \%$, respectively. Measurements of ambient $S_{c}$ in clouds have indicated that the $S_{c}$ value is usually less than $1 \%$ and almost never exceeded $2 \%$ and a median value of $0.1 \%$ was reported (Seinfeld and Pandis, 1998). At the $S_{c}$ value of $0.1 \%$, the concentration of the resulting activated $\mathrm{CCN}$ is on the order of several hundred per $\mathrm{cm}^{3}$, consistent with the order of magnitude of the droplet concentrations in low-level clouds, such as stratus (Seinfeld and Pandis, 1998). At $S_{c}=0.1 \%$, EC particles of $0.42 \mu \mathrm{m}$ after cloud processing was calculated to grow to $0.86 \mu \mathrm{m}$ in an open system scenario. In a closed system scenario, a cloud cycle could only transform a maximum of $100 \%$ of gas-phase $\mathrm{SO}_{2}$, leading to growth of the original EC particles of $0.42 \mu \mathrm{m}$ to $0.78 \mu \mathrm{m}$ at $S_{c}=0.1 \%$.

Our calculations assuming either an open or a closed system scenario indicates that in-cloud processing is a possible mechanism for the growth of EC particles in the 0.32$0.56 \mu \mathrm{m}$ size bin to the $0.56-1.0 \mu \mathrm{m}$ size bin in the atmosphere of Shenzhen. This conclusion is similar to the observation reported for sulfate aerosol in the 1987 Southern California Air Quality Study (SCAQS). Sulfate was observed to have two modes in the accumulation size range, with one peaking at $0.2 \mu \mathrm{m}$ (the condensation mode) and the other one peaking at $0.7 \mu \mathrm{m}$ (the droplet mode). Numerical analyses by Meng and Seinfeld (1994) and by Kerminen and Wexler (1995) demonstrated that in-cloud formation was the only possible mechanism for the growth of condensationmode sulfate to droplet-mode sulfate. Although the prevalent 
meteorological conditions and the aerosol chemical composition are different in the PRD region and in Southern California, it is clear that in-cloud formation of sulfate is the primary mechanism that causes ambient aerosol particles that are less than $0.5 \mu \mathrm{m}$ grow to $0.7 \mu \mathrm{m}$ or larger.

Our calculations were based on using the atmospheric conditions in the PRD region during the summer. It can be similarly argued that the EC modal peak in the $0.56-1.0 \mu \mathrm{m}$ size bin observed in the winter samples is caused by in-cloud processing of freshly emitted EC particles. The cloud amount (i.e., percentage of the sky covering by clouds) was lower in the winter than in the summer, but still significant in the winter. Observations of the daily cloud amount were available for the neighboring city of Hong Kong (available at www.hko.gov.hk). During the summer sampling periods, the daily cloud amount in Hong Kong was on average $67 \%$ and ranged from $16 \%$ to $90 \%$ while in the winter sampling periods, the daily cloud amount was on average $52 \%$ and ranged from $14 \%$ to $87 \%$. In comparison with the summer sampling periods, the infrequent rainfall in the winter sampling periods increased the likelihood of in-cloud processing through prolonged lifetimes for aerosols.

\subsection{Implications for the EC mixing state}

The above analysis reveals that in-cloud processing is the primary mechanism leading to the growth of EC particles in the $0.32-0.56 \mu \mathrm{m}$ size bin to the next larger size bin. The residue particles after cloud processing consist of internally mixed $\mathrm{EC}$ and $\left(\mathrm{NH}_{4}\right)_{2} \mathrm{SO}_{4}$. By assuming that either all the $\mathrm{EC}$ is from vehicular emissions or other EC sources had similar EC size distribution patterns to EC from vehicular emissions, it is possible to estimate the fraction $(R)$ of internally mixed EC particles due to cloud processing using Eq. (3):

$$
\begin{aligned}
& R=\left(\alpha_{a}-\alpha_{V}\right)+\left(\alpha_{a}-\alpha_{V}\right) \times \frac{\alpha_{V}}{1-\alpha_{V}}, \\
& \quad=\left(\alpha_{a}-\alpha_{V}\right) /\left(1-\alpha_{V}\right)
\end{aligned}
$$

where $\alpha_{a}$ and $\alpha_{v}$ are the mass fraction of EC in the 0.56$3.2 \mu \mathrm{m}$ size range out of all EC mass in the accumulative size range (i.e., $0.056-3.2 \mu \mathrm{m}$ ) in the ambient atmosphere and in vehicular emissions, respectively; $\left(1-\alpha_{v}\right)$ is the mass fraction of EC in particles $<0.56 \mu \mathrm{m}$ that are freshly emitted from vehicles; $\left(\alpha_{a}-\alpha_{v}\right)$ is the percentage gain of EC mass in the droplet size range (i.e., $0.56-3.2 \mu \mathrm{m}$ ). This gain is mainly attributable to EC particles $<0.56 \mu \mathrm{m}$ growing into the $0.56-3.2 \mu \mathrm{m}$ size bin through in-cloud processing. In a cloud event, when a portion of EC particles $<0.56 \mu \mathrm{m}$ grows into particles $>0.56 \mu \mathrm{m}$, the larger EC particles $(>0.56 \mu \mathrm{m})$ in the same air volume must also experience in-cloud processing and become internally mixed because larger particles are more easily activated in clouds. The corresponding amount of larger particles that also experience in-cloud processing is $\left(\alpha_{a}-\alpha_{v}\right) \times\left(\alpha_{v} / 1-\alpha_{v}\right)$. The total internally mixed EC fraction $(R)$ is therefore the sum of the two. When $R$ is calculated this way, it is the lower limit estimate for the fraction of internally mixed EC, since other mechanisms (e.g., vapor condensation) can also lead to internal mixing of EC with sulfate but have not been considered in our estimation.

Using Eq. (3) and the average size distributions shown in Fig. 2, we calculated the mass fraction of internally mixed $\mathrm{EC}$ due to in-cloud processing in the accumulative size range to be $32 \%$ in the summer samples ( $22 \%$ in the Group L samples and 39\% in the Group H samples) and $43 \%$ in the winter samples. In the droplet size range, the mass fraction of internally mixed EC was calculated to be $45 \%$ (Group L summer samples), 64\% (Group H summer samples), and 68\% (winter samples). The uncertainty for these fraction values, obtained by compounding the uncertainty of each parameter in Eq. (3), was estimated to be less than $5 \%$.

Cheng et al. (2006) recently studied the aerosol mixing state of EC at Xinken, a rural location in the PRD region, in October 2004 using in situ aerosol microphysical and chemical measurements and a two-component aerosol optical model. They reported that internally mixed EC accounted for $5 \% \sim 47 \%$ of the total EC mass under different meteorological conditions. Our estimate was in broad agreement with their estimates. That is, internally mixed EC accounts for a substantial fraction of the total $\mathrm{EC}$ in this region. Cheng et al. (2006) also observed that there was a fairly rapid local aging process transforming EC from external mixing to internal mixing. Our results show that in-cloud processing is likely the primary process that causes the rapid aging of EC.

\section{Conclusions}

We studied the size distribution characteristics of EC in the urban environment of the Pearl River Delta Region in China. The majority of EC $(\sim 80 \%)$ was found on fine particles less than $3.2 \mu \mathrm{m}$ in diameter. A consistent bimodal size distribution pattern was observed in the size range of $0.056-18 \mu \mathrm{m}$ in all samples. The fine mode peaked either at $0.42 \mu \mathrm{m}$ or $0.75 \mu \mathrm{m}$. The mode at $0.42 \mu \mathrm{m}$ could be ascribed to fresh vehicular emissions in this region, while the mode at $0.75 \mu \mathrm{m}$ was shown to be a result of in-cloud processing as determined by theoretical investigation of particle growth mechanisms. In-cloud processing leads to internally mixed EC and sulfate particles. Comparison of the EC size distributions in fresh vehicular emissions and in the ambient environment gave a lower end estimate of $45-64 \%$ of the EC mass in the summer samples and $68 \%$ of EC mass in the winter samples in the droplet size range being internally mixed. Since the absorbance coefficients of particles of internally mixed EC and sulfate ammonium are much higher than in externally mixed $\mathrm{EC}$, the fraction of internally mixed EC should be considered in modeling atmospheric optical properties in this region.

Acknowledgements. The work was supported by the Research Grants Council of Hong Kong (621405). We thank Prof. LingYan $\mathrm{He}$ at Peking University for support during sampling. The 
authors gratefully acknowledge the NOAA Air Resources Laboratory (ARL) for the provision of the HYSPLIT transport and dispersion model and READY website (http://www.arl.noaa.gov/ready. html) used in this publication.

\section{References}

Allen, J. O., Mayo, P. R., Hughes, L. S., Salmon, L. G., and Cass, G. R.: Emissions of size-segregated aerosols from on-road vehicles in the Caldecott tunnel, Environ. Sci. Technol., 35, 4189-4197, 2001.

Andreae, M. O. and Gelencser, A.: Black carbon or brown carbon? The nature of light-absorbing carbonaceous aerosols, Atmos. Chem. Phys., 6, 3131-3148, 2006, http://www.atmos-chem-phys.net/6/3131/2006/.

Birch, M. E. and Cary, R. A.: Black carbon-based method for monitoring occupational exposures to particulate diesel exhaust, Aerosol. Sci. Technol., 25, 221-241, 1996.

Bond, T. C., Streets, D. G., Yarber, K. F., Nelson, S. M., Woo, J. H., and Klimont, Z.: A technology-based global inventory of black and organic carbon emissions from combustion, J. Geophys. Res., 109(D14), D14203, doi:10.1029/2003JD003697, 2004.

Cabada, J. C., Pandis, S. N., and Robinson, A. L.: Sources of atmospheric carbonaceous particulate matter in Pittsburgh, Pennsylvania, J. Air \& Waste Manage. Assoc., 52, 732-741, 2002.

Cao, J. J., Lee, S. C., Ho, K. F., Zou, S. C., Fung, K., Li, Y., Watson, J. G., and Chow, J. C.: Spatial and seasonal variations of atmospheric organic carbon and elemental carbon in Pearl River Delta Region, China, Atmos. Environ., 38, 4447-4456, 2004.

Chang, M. C., Kim, S., and Sioutas, C.: Experimental studies on particle impaction and bounce: effects of substrate design and material, Atmos. Environ., 33, 2313-2322, 1999.

Cheng, Y. F., Eichler, H., Wiedensohler, A., et al.: Mixing state of elemental carbon and non-light-absorbing aerosol components derived from in situ particle optical properties at Xinken in Pearl River Delta of China, J. Geophys. Res., 111, D20204, doi:10.1029/2005JD006929, 2006.

Chow, J. C., Watson, J. G., and Pritchett, L. C.: The DRI ther$\mathrm{mal} /$ optical reflectance carbon analysis system: description, evaluation and applications in US air quality studies, Atmos. Environ., 27A, 1185-1201, 1993.

Chuang, P. Y., Duvall, R. M., Bae, M. S., Jefferson, A., Schauer, J. J., Yang, H., Yu, J. Z., and Kim, J.: Observations of elemental carbon and absorption during ACE-Asia and implications for aerosol radiative properties and climate forcing, J. Geophys. Res., 108(D23), 8634, doi:10.1029/2002JD003254, 2003.

Draxler, R. R. and Rolph, G. D.: HYSPLIT (HYbrid Single-Particle Lagrangian Integrated Trajectory) Model access via NOAA ARL READY Website (http://www.arl.noaa.gov/ready/hysplit4.html). NOAA Air Resources Laboratory, Silver Spring, MD, USA, 2003.

Ervens, B., George, C., Williams, J. E., Buxton, G. V., Salmon, G. A., Bydder, M., Wilkinson, F., Dentener, F., Mirabel, P., Wolke, R., and Herrmann, H.: CAPRAM 2.4 (MODAC mechanism): An extended and condensed tropospheric aqueous phase mechanism and its application, J. Geophys. Res., 108(D14), 4426, doi:10.1029/2002JD002202, 2003.
Feingold, G., Kreidenweis, S. M., and Zhang, Y.: Stratocumulus processing of gases and cloud condensation nuclei. 1. Trajectory ensemble model, J. Geophys. Res., 103, 19527-19542, 1998.

Fuller, K.A., Malm, W.C., and Kreidenweis, S.M.: Effects of mixing on extinction by carbonaceous particles. J. Geophys. Res., 104(D13):15 941-15 954, 1999.

Hagler, G. S. W., Bergin, M. H., Salmon, L. G., Yu, J. Z., Wan, E. C. H., Zheng, M., Zeng, L. M., Zhang, Y. H., Lau, A. K. H., and Schauer, J. J.: Source areas and chemical composition of fine particulate matter in the Pearl River Delta region of China, Atmos. Environ., 40, 3802-3815, 2006.

Hansen, J., Sato, M., Ruedy, R., Lacis, A., and Oinas, V.: Global warming in the twenty-first century: an alternative scenario, Proc. Natl. Academy Sci., 97, 9875-9880, 2000.

Haywood, J. M. and Shine, K. P.: The effect of anthropogenic sulphate and soot aerosol on the clear sky planetary radiation budget, Geophys. Res. Lett., 22, 603-606, 1995.

Hitzenberger, R. and Tohno, S.: Comparison of black carbon (BC) aerosols in two urban areas - concentrations and size distribution, Atmos. Environ., 35, 2153-2167, 2001.

Horvath, H.: Atmospheric light absorption - a review, Atmos. Environ., 27A, 293-317, 1993.

Huang, X. F., Yu, J. Z., He, L. Y., and Hu, M.: Size distribution characteristics of elemental carbon emitted from Chinese vehicles: Results of a tunnel study and atmospheric implications, Environ. Sci. Technol., 44, 5355-5360, 2006a.

Huang, X.-F., Yu, J. Z., He, L.-Y. and Yuan, Z.: Watersoluble organic carbon and oxalate in aerosols at a coastal urban site in China: Size distribution characteristics, sources, and formation mechanisms, J. Geophys. Res., 111, D22212, doi:10.1029/2006JD007408, 2006b.

Jacobson, M. Z.: A physically-based treatment of elemental carbon optics: Implications for global direct forcing of aerosols, Geophys. Res. Lett., 27, 217-220, 2000.

Jacobson, M. Z.: Strong radiative heating due to the mixing state of black carbon in atmospheric aerosols, Nature, 409, 695-697, 2001.

Jaffrezo, J.-L., Aymoz, G., and Cozic, J.: Size distribution of EC and $\mathrm{OC}$ in the aerosol of Alpine valleys during summer and winter, Atmos. Chem. Phys., 5, 2915-2925, 2005, http://www.atmos-chem-phys.net/5/2915/2005/.

Kadowaki, S.: Characterization of carbonaceous aerosols in the Nagoya urban area. 1. Elemental and organic carbon concentrations and the origin of organic aerosols, Environ. Sci. Technol., 24, 741-744, 1990.

Kerminen, V.-M. and Wexler, A. S.: Growth laws for atmospheric aerosol particles: An examination of the bimodality of the accumulation mode, Atmos. Environ., 29, 3263-3275, 1995.

Kerminen, V.-M., Mäkelä, T. E., Ojanen, C., Hillamo, R. E., Vilhunen, J. K., Rantanen L., Havers, N., and Bohlen, A. V., and Klockow, D.: Characterization of the particulate phase in the exhaust from a diesel car, Environ. Sci. Technol., 31, 1883-1889, 1997.

Kerminen, V.-M., Pirjola, L., Boy, M., et al.: Interaction between SO2 and submicron atmospheric particles, Atmos. Res., 54, 41$57,2000$.

Kleeman, M. J., Schauer, J. J., and Cass, G. R.: Fine particulate matter emitted from wood burning, meat charbroiling, and cigarettes, Environ. Sci. Technol. 33, 3516-3523, 1999. 
Kleeman, M. J., Schauer, J. J., and Cass, G. R.: Size and composition distribution of fine particulate matter emitted from motor vehicles, Environ. Sci. Technol., 34, 1132-1142, 2000.

Langner, J. and Rodhe, H.: A global 3-dimentional model of the tropospheric sulfur cycle, J. Atmos. Chem., 13, 225-263, 1991.

Lesins, G., Chylek, P., and Lohmann, U.: A study of internal and external mixing scenarios and its effect on aerosol optical properties and direct radiative forcing, J. Geophys. Res., 107(D10), 4094, doi:10.1029/2001JD000973, 2002.

Liang, J. and Jacobson, M. Z.: A study of sulfur dioxide oxidation pathways over a range of liquid water contents, $\mathrm{pH}$ values, and temperatures, J. Geophys. Res., 104, 13 749-13 769, 1999.

Louie, P. K. K., Watson, J. G., Chow, J. C., Chen, L. W. A., Sin, D. W. M., and Lau, A. K. H.: Seasonal characteristics and regional transport of $\mathrm{PM}_{2.5}$ in Hong Kong, Atmos. Environ., 39, 16951710, 2005.

McHenry, J. N. and Dennis, R. L.: The relative importance of oxidation pathways and clouds to atmospheric ambient sulfate production as predicted by the regional acid deposition model, J. Appl. Meteorol., 33, 890-905, 1994.

Meng, Z. and Seinfeld, J. H.: On the source of the submicrometer droplet mode of urban and regional aerosols, Aerosol Sci. Technol., 20, 253-265, 1994.

Menon, S., Hansen, J., Nazarenko, L., and Luo, Y.: Climate effects of black carbon aerosols in China and India, Science, 297, 22502253, 2002.

Nenes, A., Pilinis, C., and Pandis, S. N.: Continued development and testing of a new thermodynamic aerosol module for urban and regional air quality models, Atmos. Environ., 33, 15531560, 1998.

NIOSH: Method 5040 Issue 3: Elemental carbon (diesel exhaust), in: NIOSH manual of analytical methods, 4th ed., National Institute of Occupational Safety and Health, Cincinnati, 1999.

Pandis, S. N., Wexler, A. S., and Seinfeld, J. H.: Secondary organic aerosol formation and transport. 2. Predicting the ambient secondary organic aerosol-size distribution, Atmos. Environ., 27A, 2403-2416, 1993.

Remer, L. A., Kaufman, Y. J., Holben, B. N., Thompson, A. M., and McNamara, D.: Biomass burning aerosol size distribution and modeled optical properties, J. Geophys. Res. 103, 31 879$31891,1998$.

Rolph, G. D.: Real-time Environmental Applications and Display sYstem (READY) Website (http://www.arl.noaa.gov/ready/ hysplit4.html), NOAA Air Resources Laboratory, Silver Spring, MD, USA, 2003.

Saxena, P. and Seigneur, C.: On the oxidation of $\mathrm{SO} 2$ to sulfate in atmospheric aerosols, Atmos. Environ., 21, 807-812, 1987.

Seinfeld, J. H. and Pandis, S. N.: Atmospheric chemistry and physics: from air pollution to climate change, John Wiley, New York, 338-339, 379-380 and 808-811, 1998.
Shenzhen Environmental Protection Bureau (SZEPB): Environmental monitoring report of Shenzhen, 2005, Shenzhen, China, 2006, Chinese report online available at: http://www.szepb. gov.cn/pageInfoMore.jsp?itemID=185, last access on 9 October 2008.

ten Brink, H., Maenhaut, W., Hitzenberger, R., Gnauk, T., Spindler, G., Even A., Chi X., Bauer, H., Puxbaum, H., Putaud, J.-P., Tursic, J., and Berner, A.: INTERCOMP2000: the comparability of methods in use in Europe for measuring the carbon content of aerosol, Atmos. Environ., 38, 6507-6519, 2004.

Venkataraman, C., Lyons, J. M., and Friedlander, S. K.: Size distributions of PAHs and elemental carbon. 1. Sampling, measurement methods, and source characterization, Environ. Sci. Technol., 28, 555-562, 1994.

Venkataraman, C. and Friedlander, S. K.: Size distributions of PAHs and elemental carbon. 2. Ambient measurements and effects of atmospheric processes., Environ. Sci. Technol., 28, 563-572, 1994.

Venkataraman, C., Mehra, A., and Mhaskar, P.: Mechanisms of sulphate aerosol production in clouds: effect of cloud characteristics and season in the Indian region, Tellus, 53B, 260-272, 2001.

Viidanoja, J., Kerminen, V.-M., and Hillamo, R.: Measuring the size distribution of atmospheric organic and black carbon using impactor sampling coupled with thermal carbon analysis: method development and uncertainties, Aerosol Sci. Technol., 36, 607-616, 2002.

Warneck, P.: The relative importance of various pathways for the oxidation of sulphur dioxide and nitrogen dioxide in sunlit continental fair weather clouds, Phys. Chem. Chem. Phys., 1, 54715483, 1999.

Wexler, A. S., Lurmann, F. W., and Seinfeld J. H.: Modelling urban and regional aerosols - I. Model development, Atmos. Environ., 28, 531-546, 1994.

Yu, J. Z., Xu, J. H., Yang, H.: Charring characteristics of atmospheric organic particulate matter in thermal analysis, Environ. Sci. Technol., 36, 754-761, 2002.

Yu, J. Z., Tung, J. W. T., Wu, A. W. M., Lau, A. K. H., Louie, P. K. K., and Fung, J. C. H.: Abundance and seasonal characteristics of elemental and organic carbon in Hong Kong PM10, Atmos. Environ., 38, 1511-1521, 2004.

Yuan, Z. B., Yu, J. Z., Lau, A. K. H., Louie, P. K. K., and Fung, J. C. H.: Application of positive matrix factorization in estimating aerosol secondary organic carbon in Hong Kong and its relationship with secondary sulfate, Atmos. Chem. Phys., 6, 25-34, 2006a, http://www.atmos-chem-phys.net/6/25/2006/.

Yuan, Z. B., Lau, A. K. H., Zhang. H. Y., Yu, J. Z., Louie, P. K. K., and Fung, J. C. H.: Identification and spatiotemporal variations of dominant PM10 sources over Hong Kong, Atmos. Environ., 40, 1803-1815, 2006b. 